Biol. Proced. Online 2004;6(1): 105-112

doi:10.1251/bpo78

\title{
Expression and purification of recombinant vesicular glutamate transporter VGLUT1 using PC12 cells and High Five insect cells
}

\author{
Søren S. L. Andersen ${ }^{1 *}$ \\ 'Department of Neurology and Neurological Sciences, Stanford University, Stanford, CA 94305-5489, USA.
}

*To whom correspondence should be addressed: Søren S. L. Andersen, Email: soren@sorenandersen 1.org

Submitted: April 20, 2004; Revised: May 31, 2004; Accepted: May 18, 2004; Published: June 7, 2004.

Indexing terms: Membrane Proteins; Baculovirus; Glutamates.

\begin{abstract}
In synaptic vesicles, the estimated concentration of the excitatory amino acid glutamate is $100-150 \mathrm{mM}$. It was recently discovered that VGLUT1, previously characterized as an inorganic phosphate transporter (BNPI) with 9-11 predicted transmembrane spanning domains, is capable of transporting glutamate. The expression and His-tag based purification of recombinant VGLUT1 from PC12 cells and High Five insect cells is described. Significantly better virus and protein expression was obtained using High Five rather than Sf9 insect cells. PC12 cell expressed VGLUT1 is functional but not the Baculovirus expressed protein. The lack of functionality of the Baculovirus expressed VGLUT1 is discussed. The data indicate that VGLUT1 readily oligomerizes/dimerizes. The data are discussed in the context of developing this system further in order to reconstitute vesicular glutamate uptake in vitro using lipid-detergent vesicles.
\end{abstract}

\section{INTRODUCTION}

Synaptic communication between neurons involves the release of neurotransmitters at the nerve terminal through fusion of neurotransmitter-filled synaptic vesicles with the pre-synaptic membrane (1). Until the 1980 's, direct evidence for storage of glutamate, the major excitatory neurotransmitter in the mammalian CNS, in synaptic vesicles was lacking $(2,3)$. Biophysical studies have suggested that glutamate is present in synaptic vesicles at concentrations exceeding $100 \mathrm{mM}(2-4)$. It has been argued that vesicles are entirely filled with glutamate, and in order to be equi-osmolar with the cytoplasm they would therefore contain 100-150 mM glutamate. However, this has never been directly measured, as vesicles constantly leak glutamate, and therefore can not be purified with their full glutamate content. Moreover, an additional reason the extent of synaptic glutamate filling is poorly studied is that the cellular machinery involved in vesicular filling has remained elusive (2, 58). Recently, it was discovered that one protein able to transport glutamate into vesicles is the vesicular glutamate transporter VGLUT1 that had initially been characterized as an inorganic phosphate transporter (8-10). It is of fundamental interest to characterize how VGLUT1 transports glutamate across membranes into vesicles, and to understand what other lipid and protein requirements might be involved in order to load successfully vesicles with glutamate in vitro, and to an extent comparable to the (unknown) amounts found in synaptic vesicles in vivo.

To unravel these issues, one first needs establish an ample source of recombinant VGLUT1 for reconstitution type experiments. This paper first describes the extraction and partial purification of VGLUT1 from PC12 cells, the latter from which the protein previously was successfully expressed in a functional form (9). However, amongst drawbacks, PC12 cells grow best on a solid 
surface, rather than in suspension, and which greatly diminish the protein yield possible from this source. Thus, in order to produce readily high amounts of recombinant VGLUT1, the powerful Baculovirus expression system was attempted as an alternative to the PC12 cell based VGLUT1 expression. VGLUT1 was expressed and purified using Baculovirus, and as inspired by previous reports (11-16). Using two different assays for glutamate transport, it was found that the Baculovirus expressed VGLUT1 was not functional to any significant extent.

\section{MATERIALS AND METHODS}

\section{VGLUT1 purification from PC12 cells}

VGLUT1 containing PC12 vesicles were isolated as previously described (9). Briefly, vesicles derived from $1214 \mathrm{~cm}$ x $2 \mathrm{~cm}$ plast plates (Nunc, Cat. No. 168381) were resuspended in $0.5 \mathrm{ml} \mathrm{SH}$ buffer (in mM: 10 Hepes, 310 sucrose, $\mathrm{pH7.4)}$ at a total protein concentration of $20-30 \mathrm{mg} / \mathrm{ml}$, and stored at $-80^{\circ} \mathrm{C}$. To purify VGLUT1, a 6xHis-tag present at the N-terminus of the C35 VGLUT1 construct (parent VGLUT1 coding vector (9) with an N-terminal 6-His tag; generated by Dr. Richard Reimer) was used. The 6xHis-tag protein's affinity for Talon beads (Clontech, cat no. 8901-1) was used as a primary purification step [Talon proved better than Ni-NTA magnetic agarose beads (Sigma, cat. No. 36111)]. Binding to and extraction of VGLUT1 from the Talon beads were performed in three quick and easy steps as follows. 1) Binding: one volume of vesicles (50 $\mu \mathrm{l}$ at $20-30$ $\mathrm{mg} / \mathrm{ml}$ protein) was mixed with four volumes $(200 \mu \mathrm{l})$ of buffer A (mM: $500 \mathrm{NaCl}, 20$ HEPES pH7.5, 10\% glycerol, 1 Imidazole $\mathrm{pH} 7.5,1.2 \%$ cholate, and PMSF and peptide-protease inhibitor cocktail) that already contained one volume $(50 \mu \mathrm{l})$ Talon beads (50 $\mu \mathrm{l}$ beads were from the stock sedimented for $1 \mathrm{~min}, 10 \mathrm{krpm}$, in a table top, and $1 \mathrm{x}$ buffer-A-washed).

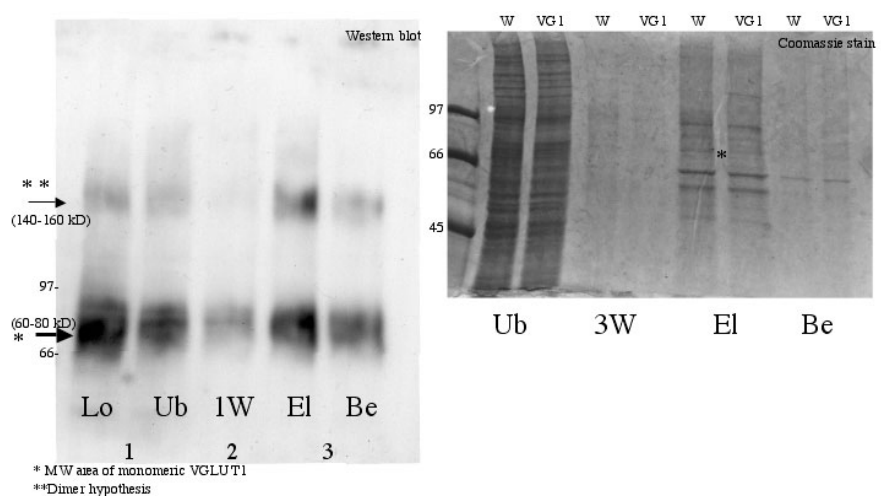

Fig. 1: Purification of VGLUT1 from PC12 cells. Left: Western blot of samples from the purification probed with polyclonal goat anti-VGLUT1 antibody. Lo shows the material that was loaded on the gel, $U b$ is the material that didn't bind to the Talon beads, $1 \mathrm{~W}$ is the protein that remained after the first wash, $E l$ is the protein eluted from the beads, and $B e$ is the protein that could not be eluted from the beads. Right: Coomassie stained gel, $W$ is for wild-type PC12 and VG1 is for VGLUT1 expressing PC12 cells. $U b$ is the amount the protein that didn't bind to the beads, $3 W$ is what came off in the third and last wash, $E l$ is what was eluted form the beads and $B e$ is what could not be eluted from the beads. * indicates the MW region for monomeric VGLUT1 and ** the MW region for oligomerized VGLUT1. The samples were resolved on $7.5 \%$ precast Bio-rad gels. Molecular weight markers are indicated.
The mix was incubated on a rotating wheel for one hour at $4^{\circ} \mathrm{C}$. 2) Washing: the Talon beads were pelleted and washed three times for five minutes, and using buffer A containing $15 \mathrm{mM}$ Imidazole $(\mathrm{pH} 7.5)$ at $4^{\circ} \mathrm{C}$. 3) Elution: VGLUT1 was eluted from the beads by incubation with buffer A containing $200 \mathrm{mM}$ Imidazole ( $\mathrm{pH} 7.5$ ) for $15-30 \mathrm{~min}$ at $4^{\circ} \mathrm{C}$ (Fig. 1).

\section{Insect cell cultures}

Both High Five and Sf9 insect cells (Gibco, Cat. No. 11496-015) were used in this study. High Five cells (from Alex Bankovich) were used for virus propagation and protein expression and grown at $28^{\circ} \mathrm{C}$ at a density of $1-7 \times 10^{6}$, rotating at $200-250 \mathrm{rpm}$ in $50 \mathrm{ml}$ cultures in shaker flasks in serum-free Insect-Xpress medium (BioWhittaker, Cat. No. 12-730Q) supplemented with 33

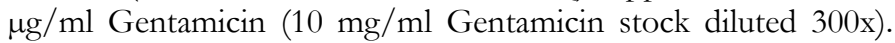
Initially, Sf9 cells were used for virus production. They were grown at $28^{\circ} \mathrm{C}$ in Sf-900 II SFM (Gibco, Cat. No. 10902-096). However, although the Sf9 cells were provided as "serum-free adapted" from the factory, it was necessary to supplement the Sf900 II medium with 5\% Cosmic Calf Serum (HyClone, Cat. No. SH30087.03). Without serum addition, the cells grew either 1) slowly as adherent cultures, 2) stayed alive without significant growth in spinner flask cultures, and 3) died in shaker flask cultures. However, addition of $5 \%$ serum solved this problem, and allowed propagation and normal cell growth (18 hrs. doubling time) in adherent, spinner and shaker flask cultures. All media for growth of Sf9 cells were therefore supplemented with $5 \%$ serum, and cultures were grown in shaker flasks rotating at $200-250 \mathrm{rpm}$, with $50 \mathrm{ml}$ culture, and with a density of $1-10 \times 10^{6}$ cells $/ \mathrm{ml}$. The medium was also supplemented with either Penicillin-Streptomycin (diluted 500x; Gibco, Cat. No. 15140 $122 ;$ Penicillin at 10,000 units/ml, and Streptomycin at $10 \mathrm{mg} / \mathrm{ml}$ ) or with $10 \mathrm{mg} / \mathrm{ml}$ Gentamicin (diluted 300x; Gibco, Cat. No. 15710-064) stock solution.

\section{Generation of a VGLUT1 coding transfer plasmid}

Sapphire ${ }^{\mathrm{TM}}$ Baculovirus DNA (Orbigen, Cat. No. bvd-10001) in combination with transfer plasmid pAcMP2 (gift from Dr. Aaron Schaefer) were used as tools to generate a recombinant VGLUT1 coding Baculovirus. Thus, VGLUT1 was by a single XbaI cut excised from construct $\mathrm{C} 35$ and then ligated into the $\mathrm{XbaI}$ site of the pAcMP2 polylinker region, giving the pAcMP2-VGLUT1 vector. The correct orientation of VGLUT1 in pAcMP2VGLUT1 was determined by a BamHI restriction digest (data not shown). The first $650 \mathrm{nt}$ of the coding sequence were sequenced and verified to have the correct sequence; in this construct, the start ATG codon is located 40 nt down-stream of the $\mathrm{XbaI}$ site in the $\mathrm{pAcMP} 2$ polylinker.

\section{Preparation of VGLUT1 coding Baculovirus}

With the Sapphire DNA approach, a cotransfection of the coding plasmid with the linearized Baculovirus Sapphire DNA is the first step. To transfect Sf9 insect cells, $1 \mu \mathrm{g}$ of pAcMP2-VGLUT1 was 
mixed with $0.5 \mu \mathrm{g}$ Sapphire ${ }^{\mathrm{TM}}$ DNA (the DNA mix), and the mix incubated for $10 \mathrm{~min}$ at room temperature, after which $500 \mu \mathrm{l}$ Grace's medium (Gibco, Cat. No. 11605-094) without serum was added. In a different tube, $15 \mu \mathrm{l}$ Cellfectin (Invitrogen, Cat. No. 10362-010) was mixed with $500 \mu \mathrm{l}$ Grace's medium without serum (the Cellfectin mix). The DNA and Cellfectin mixes were combined (the transfection mix), and left at room temperature for 15-30 min during which time 5-10 x $10^{6}$ Sf9 cells in log-phase (at $1-3 \times 10^{6} / \mathrm{ml}$ ) were pelleted in a clinical bench centrifuge (speed 4) in a $50 \mathrm{ml}$ Corning tube for about 5-10 min. To start the transfection, the pelleted cells were gently resuspended in the transfection mix, and this suspension incubated in a $50 \mathrm{ml}$ Corning tube in a shaker at $27^{\circ} \mathrm{C}$ for 5 hours, and with loosened cap for aeration, and at $200-250 \mathrm{rpm}$ (to prevent cell sedimentation in the relatively narrow $50 \mathrm{ml}$ tube). Following this 5-hour incubation, $4 \mathrm{ml}$ complete Sf9 medium with 5\% serum was added to the cells. The days following the transfection, cell viability and density were monitored every day using a haemocytometer and 1\% Trypan blue (Sigma) to stain for viable cells. Under optimal conditions, a total 30-60\% increase in cell density (thus, less than one full doubling) is observed, and one should keep the cells at about $3 \times 10^{6} / \mathrm{ml}$. Successful transfection/virus production was monitored by observing arrest of cell growth and/or cell death at later time points (after 3 to as many as 8 days). VGLUT1 protein expression was observed by Western blotting, and peaked at about day 5 post transfection (Fig. 2). However, it proved more difficult to obtain virus from this transfection supernatant for virus amplification (see next section).

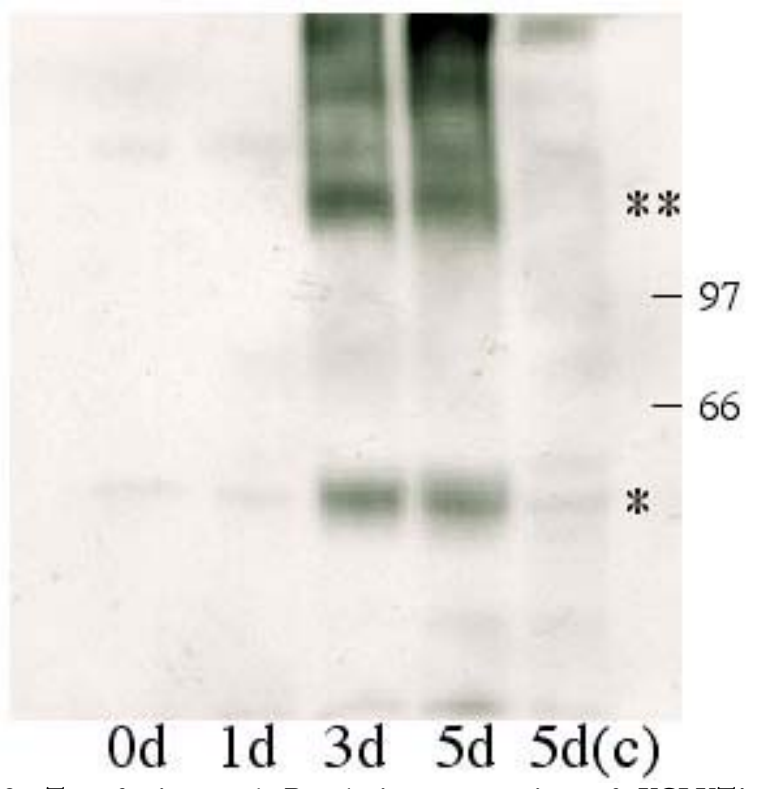

Fig. 2: Transfection and Baculovirus expression of VGLUT1. For Baculovirus production, $\mathrm{S} f 9$ cells were co-transfected with linearized Baculovirus DNA (Orbigen) and the pAcMP2 transfer vector. $5 \mu \mathrm{l}$ Culture supernatant was loaded on a gel at the days indicated. In the control $(c)$, a XylE coding plasmid (Orbigen) was used; expression of VGLUT1 is observed after three days but is absent in the control transfected line at any time. * indicates the MW region for monomeric VGLUT1 and ** the MW region for the oligomerized VGLUT1. Note: virus was not detected in the transfection supernatant until seven days after transfection.

\section{A PCR assay for detection and titration of recombinant Baculovirus}

In order to detect recombinant virus production, an assay was developed where the supernatant from the transfection step was harvested and PCR-screened for the presence of VGLUT1containing virus/DNA sequence. This approach was adopted, as propagation of the virus from the 3-5 day transfection supernatant failed, and screening of more time points was found necessary.
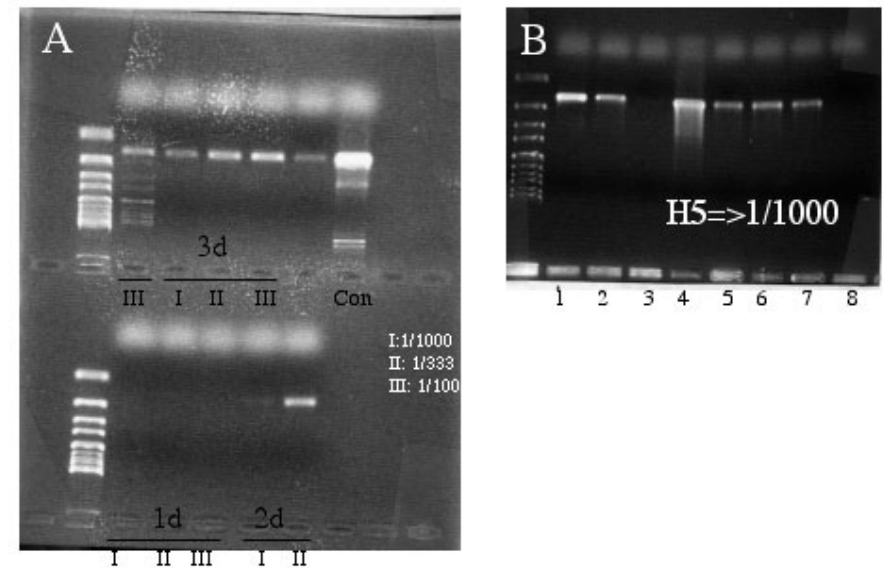

Fig. 3: Titration and propagation of VGLUT1 Baculovirus. (A) VGLUT1containing Baculovirus culture supernatant was added to Sf9 cells at the (III) 1/100, (II) $1 / 333$, and (I) $1 / 1000$ fold dilutions indicated. 2 days (2d;black numbers on gel) after infection virus could by PCR be detected with the (II) 1/333- and the (III) $1 / 100$ but not at the (I) $1 / 1000$ dilution. Virus production plateaued after 2 days and didn't appear to increase further. Con is a PCR reaction made with the transfer plasmid harboring VGLUT1, and the lane to its left is the PCR product from the VGLUT1 containing culture supernatant used in this propagation assay at the three indicated dilutions $(I, I I, I I I)$. (B) In a comparison of various conditions of VGLUT1 Baculovirus amplification, it was found that by using High Five cells, significantly more VGLUT1-Baculovirus was amplified (lane $4 ; H 5=>1 / 1000$ ) using an initial $1 / 1000$ virus dilution than with any other Sf9 cell condition (the remaining lanes). Prior to using the High Five cells, the virus was attempted concentrated by centrifugation at $45 \mathrm{krpm}$, SW50 rotor, for $60 \mathrm{~min}$ at $4^{\circ} \mathrm{C}$. Lane 3 is the supernatant, and shows that no virus was left after centrifugation (lane 1 is the PCR product derived from the pellet fraction).

For the PCR reaction, $200 \mu \mathrm{l}$ culture supernatant was mixed with $20 \mu \mathrm{l} 20 \mathrm{mg} / \mathrm{ml}$ proteinase $\mathrm{K}$ (for removal of the viral capsid), incubated for $30 \mathrm{~min}$ at $37^{\circ} \mathrm{C}$, and the solution applied to Qiagen PCR purification kit (or DNA gel extraction kit) columns in order to purify the potential recombinant viral DNA (it was found unnecessary to shear the DNA prior to addition on the columns). Of the $10 \mu \mathrm{l}$ volume eluted from the Qiagen columns, $5 \mu \mathrm{l}$ were used in standard 30 cycle Taq-polymerase PCR reactions. The 5' and 3' VGLUT1 primers used were at the 500 bp and $1200 \mathrm{bp}$ coding region of VGLUT1 respectively, and generated a PCR fragment with a predicted size of approximately $700 \mathrm{bp}$. With this appoach, the first significant amount of virus in the Sf9 transfection-supernatant was not detected before day seven after transfection (data not shown), and explaining the failure to propagate virus using shorter (3-5 days) incubations (such long incubations are at times required; Dr. Charles Parnot, personal communication). The supernatant of the transfection 
supernatant was thus harvested seven days post transfection, and the virus amplified once by infection of High Five cells grown in serum-free Insect-Xpress medium (15). To amplify the virus, the transfection supernatant was at three different dilutions $(1 / 100$, $1 / 333,1 / 1000)$ used to infect fresh insect cells, and virus containing supernatant harvested 40-48 hours after infection (Fig. $3 \mathrm{~A})$. High Five cells were used, as they proved significantly better at producing soluble virus than Sf9 cells (Fig. 3B).

\section{VLGUT1 purification from insect cells}

Initially, protein was sought expressed using Sf9 cells. However, High Five cells grown in serum-free Insect-Xpress medium proved to give several orders of magnitude better protein expression (data not shown), and all data described here were obtained using High Five cells grown in serum-free InsectXpress medium. The High Five cells were grown as $50 \mathrm{ml}$ batch cultures in shaker flasks, and infected at a density of 1-3 x $10^{6}$, and using a 1/1000 dilution of the one-time propagated VGLUT1-hosting Baculovirus. Protein expression was detectable by Western blot after about 20 hours (Fig. 4). Longer incubations, or use of the virus at less than a 1/500 dilution, caused significant cell death (the virus pfu was not determined). At between 40 to 48 hours post infection, cells were harvested by pelleting for 5-10 min. The cell pellet was resuspended in $\mathrm{SH}$ (in mM: 310 Sucrose, 10 Hepes pH7.4) in 1/10 th the culture volume. The cells were lyzed on ice either by tip sonication for $30 x 1$ second or by passage 5-10 times through a ball-bearing cell cracker (EMBL, Heidelberg, Germany).

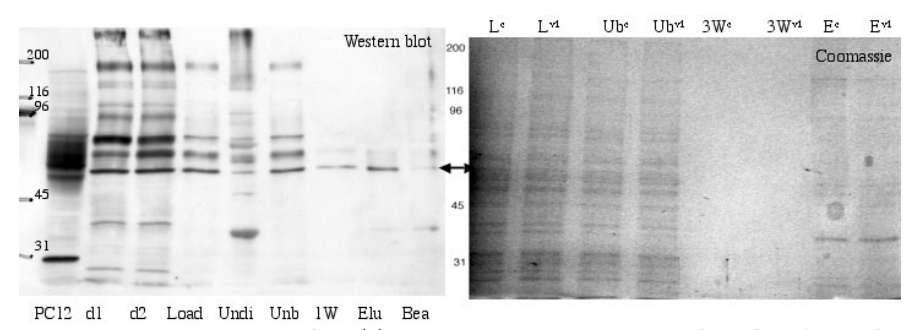

Fig. 4: Purification of VGLUT1 from High Five cells. Left: PC12 shows for comparison protein from PC12 cells (Note: 200x more PC12 than High Five total protein was loaded), $d 1$ is culture supernatant 1 day after infection, $d 2$ is culture supernatant 2 days after infection. Load is what was loaded onto the Talon beads following extraction with maltopyranoside, undi is the material that was undisolved after detergent extraction (note: 40x more loaded than in the other lanes), unb is what didn't bind the beads, $1 w$ is what came off the beads in the first wash, elu is what eluted from the beads and bea is what still remained on the beads after dilution. Right: A Commassie gel of the purification of VGLUT1 from the High Five cells; $c$ is using membranes from control infected (BVC53 virus) and $v 1$ membranes from VGLUT1 infected cells. $L$ is the material loaded on the beads, $U b$ is the material that didn't bind the beads, $3 W$ is the material that came off in the third and last wash, $E$ is what was eluted from the beads. Double arrow head indicates the region of migration of VGLUT1, and on the Commassie gel, no major band can be assigned as the recombinant VGLUT1.

The suspension was centrifuged in $1.5 \mathrm{ml}$ Eppendorf tubes and at $10 \mathrm{krpm}, 4^{\circ} \mathrm{C}, 10 \mathrm{~min}$. After the first centrifugation, a large pellet is obtained which consists of a mix of membranes, and with a fairly clear supernatant. In order to wash the pellet fraction, it was twice resuspended in the same volume of $\mathrm{SH}$, and re-pelleted. After the last centrifugation, the pellet was resuspended in $1 / 5$ th-1/10th the cell lysis volume (or $0.5-1 \mathrm{ml}$ ), and the pellet stored at $-80^{\circ} \mathrm{C}$. Using the PC12 cell VGLUT1 purification protocol, it proved impossible to extract any VGLUT1 from the insect cell membranes using Cholate or CHAPS (data not shown). By replacing CHAPS/Cholate with 1\% Decyl- $\beta$-maltopyranoside (Anatrace \#D322S), and incubating for 60-90 $\mathrm{min}$, it was possible to extract VGLUT1 from the pellet (Fig. 4), and to continue with the purification as described for the PC12 protein. Note: for both the PC12 and the insect cell purifications, the amount of detergent can be lowered to $0.5 \%$ during the washing step which saves reagents.

\section{Testing the functionality of insect cell expressed VGLUT1}

To test whether the Baculovirus expressed VGLUT1 was functionally active for glutamate transport, the assay previously described (9) was used. Using this assay, PC12 derived VGLUT1 vesicles over a 2 min assay time accumulated $2-10$ fold more ${ }^{3} \mathrm{H}$ Glutamate than control PC12 vesicles (data not shown). In the experiments reported in Figure 5, where Baculovirus infected membranes were used, both ATP and Valinomycin (in combination with high potassium) were simultaneously applied. The assay time was $2 \mathrm{~min}$, and longer incubations did not alter the results (data not shown). The buffer used in these experiments contains (in mM: $125 \mathrm{KSO}_{4}, 4 \mathrm{KCl}, 4 \mathrm{MgCl}_{2}, 10 \mathrm{~L}$ Aspartate, 0.4 L-Glutamate, 1 ATP, 1/100 3H-Glutamate [NEN] and $1 / 200$ Valinomycin $(20 \mu \mathrm{M}$ final $)$.

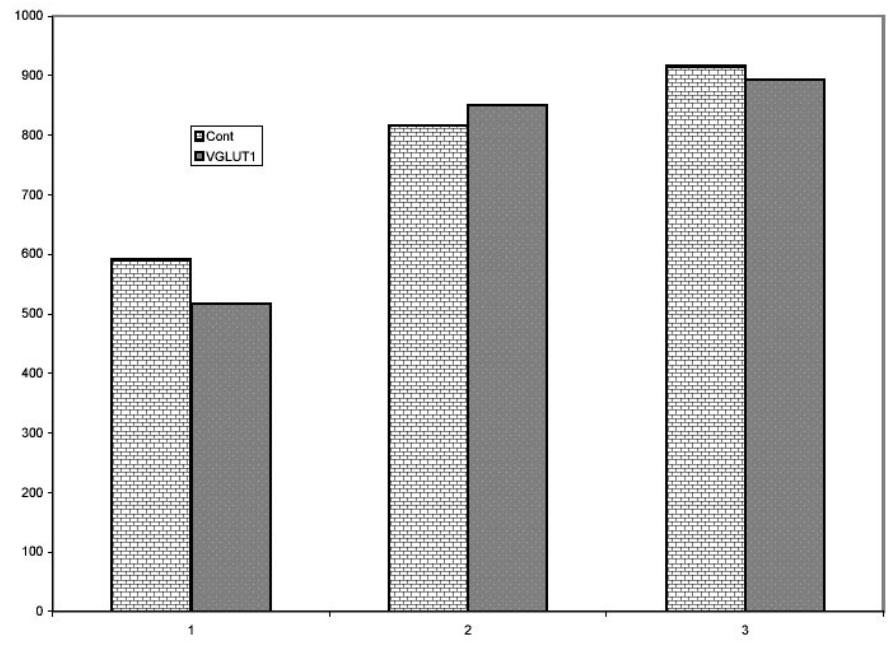

Fig. 5: ${ }^{3} \mathrm{H}$-glutamate transport assay with Baculovirus infected High Five cell membranes. $30 \mu \mathrm{l}$ of the crude membranes from VGLUT1 or BVC53 infected cells were used per reaction in a transport assay where ATP, Valinomycin, and $125 \mathrm{mM}$ potassium sulfate were applied to the outside (see materials and methods). (1) shows the ${ }^{3} \mathrm{H}$-glutamate counts obtained at the zero time point, (2) shows the counts obtained after 2 min (note the identical response for VGLUT1 and BVC53 infected cells), and (3) is the 2 min control time point, where Nigericin was included in the buffer $(\mathrm{n}=2)$. Note that little, if any (nonspecific binding increases with time), uptake occurs between the zero and the two minute time point, and that there is no difference between the samples with and without Nigericin.

In the control reaction, Nigericin (5 $\mu \mathrm{M}$ final) was added and ATP omitted. Aspartate was included to reduce non-specific 
binding, and the $0.4 \mathrm{mM}$ cold glutamate (as opposed to the 0.1 $\mathrm{mM}$ used by (9)) was used to partially block potential highaffinity plasma-membrane glutamate transporters (the $\mathrm{K}_{\mathrm{m}}$ of VGLUT1 for glutamate is about $2 \mathrm{mM}$ (9)). A Baculovirus coding for the $\beta$-adrenergic 2 receptor (BVC53; gift from Dr. Charles Parnot) was used for control infections. For the exchange experiment (Fig. 6), the cells were pelleted and resuspended in $28^{\circ} \mathrm{C}$ medium containing $1 / 50{ }^{3} \mathrm{H}$-glutamate (NEN), $10 \mathrm{mM}$ L-Aspartate and $0.5 \mathrm{mM}$ cold glutamate. For each time point, $50 \mu \mathrm{l}$ of this cell suspension (at about $5 \times 10^{6}$ cells $/ \mathrm{ml})$ was diluted with $1 \mathrm{ml}$ cold wash buffer $(110 \mathrm{mM}$ Tartrate), and the solution immediately applied onto a nitrocellulose filter (0.65 $\mu \mathrm{m}$ DAWP, Millipore; (12)) followed by two washes with $2.5 \mathrm{ml}$ cold Tartrate buffer.

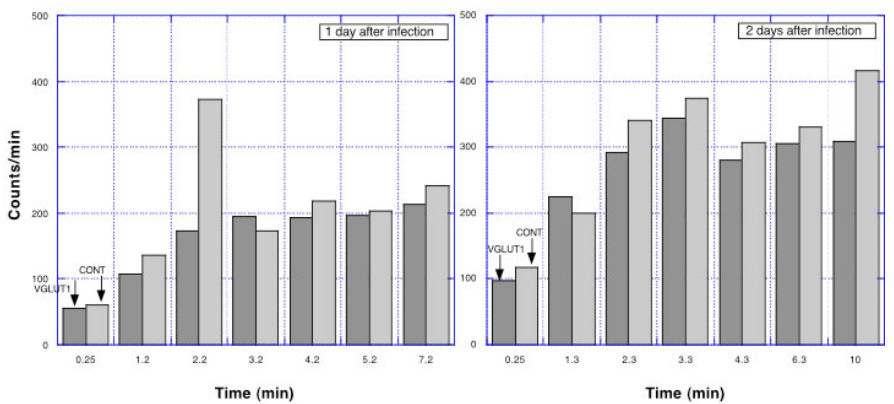

Fig. 6: ${ }^{3} \mathrm{H}$-glutamate exchange assay with intact Baculovirus infected High Five cells. Intact High Five cells were incubated in culture medium with ${ }^{3} \mathrm{H}$ glutamate. After the time indicated (minutes), the cells were isolated on a membrane, washed with buffer and subjected to Scintillation counting. Columns are VGLUT1 (left) infected and CONT/BVC53 (right) infected cells respectively; the left graph shows uptake 1 day after infection, and the right graph uptake 2 days after infection $(n=2)$.

\section{RESULTS}

\section{Purification of VGLUT1 from PC12 cells}

In order to further characterize VGLUT1, stable transfectants of VGLUT1-harboring PC12 cells (9) were used for the development of an easy and fast purification protocol. The protocol has three steps: 1) solubilization and binding to metal beads, 2) washing, and 3) elution (Fig. 1). A Histidine tag on VGLUT1 was used for the affinity purification, and the $\mathrm{N}$ terminally His-tagged protein gave better purification results than the equivalent $\mathrm{C}$-terminally tagged protein (both proteins are equally functionally active; data not shown). All results reported here were therefore performed using the N-terminally tagged protein. To extract VGLUT1 from the membrane, vesicles were resuspended in a buffer containing 1.2\% Cholate (or 1.2\% CHAPS), and then immediately mixed with Talon beads. Following washing, associated proteins were eluted with Imidazole (Fig. 1). Roughly 50\% of the total amount of VGLUT1 was bound to the beads, and most of that protein came off during the elution step (Fig. 1). Talon beads, which employ Cobalt to chelate the His-tag, were used for the affinity purification as trial experiments proved them better than $\mathrm{Ni}$ based beads (data not shown). In particular, with the Ni-based beads, a lot of protein could not be eluted whereas the Co-based beads allowed elution of associated VGLUT1 much more readily (data not shown). Interestingly, although gel samples were prepared at room temperature (as opposed to boiling) in standard Laemmli buffer (containing SDS and $\beta$-mercaptoethanol), a band roughly in the region of $140-160 \mathrm{kD}$ (twice that of monomeric VGLUT1) was reproducibly observed on Western blots, and suggesting that VGLUT1 readily forms oligomers/dimers (Fig. $1 \mathrm{~A}$, marked with two stars). Boiling of the samples for 1-2 min prior to gel loading did not decrease or increase the amount of the 140-160 $\mathrm{kD}$ band, but rather diminished the detectable amount of VGLUT1, and thus indicating that even higher oligomeric forms/aggregates were generated (data not shown;note smear at the top of the gel). The amounts of protein eluted from the beads did not, compared with the control cells, allow specific assignment of a band on the gel to VGLUT1 (Fig. 1B), and indicating that the expression levels and amounts of VGLUT1 obtainable from PC12 cells is moderate. Indeed, for the generation of $50 \mu \mathrm{l}$ VGLUT1 containing vesicles (at 20-30 $\mathrm{mg} / \mathrm{ml}$ total protein) used in this purification, all cells from 2 tissue culture plates (about $2 \times 10^{7}$ cells;using a total of $40 \mathrm{ml}$ medium) were the starting material. Therefore, as previous reports have demonstrated functional membrane protein expression using insect cells, the reagents required for Baculovirus expression of VGLUT1 were generated.

\section{Baculovirus expression of VGLUT1}

The state-of-the art approach for production of recombinant Baculovirus involves the co-transfection of a piece of linearized Baculovirus DNA with a transfer plasmid harboring the gene of interest. Reportedly, more than $90 \%$ of the virus produced using this method is recombinant, and no cumbersome screening steps are required (http://www.orbigen.com). After the transfection, VGLUT1 protein expression could be detected by Western blotting after 3 days, whereas control transfected cells (XylE control from Orbigen) didn't show any VGLUT1 expression (Fig. 2). Interestingly, the protein expressed after transfection migrated at lower molecular weight (about $50 \mathrm{kD}$ ) than the protein from PC12 cells (Fig. 1; discussion). Initial attempts at propagating recombinant virus using the supernatant from 5 day old cells proved unsuccessful (data not shown). Consequently, to more readily detect the presence of virus in the culture supernatant, a PCR-based detection approach was developed. Recombinant VGLUT1 virus was not observed earlier than 7 days after transfection (data not shown), and explaining the failure to propagate vira from earlier time points. During this amplification process, it was discovered that the recombinant virus was much better amplified using High Five cells grown in serum free InsectXpress medium than using Sf9 cells (Fig. 3B). Following this observation, all subsequent experiments were performed using High Five cells grown in serum free InsectXpress medium. To propagate the virus, transfection supernatant were at three different dilutions used to infect insect cells, and virus harvested 40-48 hours after infection (Fig. 3A). The virus from the amplification was titered by observing the 
viability of the infected High Five cells. It was found that at a $1 / 1000$-fold virus dilution, very good protein expression and cell viability was obtained. Cells were for protein purification harvested 40-48 hours after infection.

\section{Purification of VGLUT1 from High Five cells}

VGLUT1-Baculovirus infected cells were harvested by centrifugation, and lysed at $4^{\circ} \mathrm{C}$ by brief sonication or with a cell cracker. Crude membranes were prepared by pelleting the lysed cells at $4^{\circ} \mathrm{C}$, at $10,000-20,000 \mathrm{~g}$ for $15 \mathrm{~min}$ (12). Most of VGLUT1 was observed in the pellet/crude membrane fraction, and little in the supernatant (data not shown). Using these crude membranes as starting material, and in order to purify VGLUT1 from the High Five cells, the protocol developed for use with the PC12 cells was initially applied. However, it proved impossible to extract any VGLUT1 from the insect cell membranes using Cholate or CHAPS (data not shown), and no protein was found bound to the Talon beads using these conditions (data not shown). Previous accounts on Baculovirus-expression of membrane proteins have indicated that Cholate (or CHAPS) extract poorly proteins from insect cell membranes (14). Guided by these observations (14), by substituting Cholate/CHAPS with $1 \% \mathrm{n}$-decyl- $\beta$-d-maltopyranoside, and using otherwise identical conditions to those used for the PC12 based purification, it was found possible to extract VGLUT1 from the insect cell membranes (Fig. 4). However, even after a 90 min extraction, a significant amount of insoluble material remained, which a western blot showed contained significant amounts of VGLUT1, and thus indicating that the protein was aggregated already prior to the detergent extraction (Fig. 4).

\section{Testing the functionality of Baculovirus expressed VGLUT1}

To test whether VGLUT1 expressed in the insect cells was functionally active, the assay used with PC12 cell vesicles was applied (9). In this assay, vesicular VGLUT1 containing membranes are incubated in a buffer containing ${ }^{3} \mathrm{H}$-glutamate and ATP, and ${ }^{3} \mathrm{H}$-counts $2-10$ fold over control vesicles is routinely observed (data not shown; (9)). The energy for transport of glutamate across the membrane is derived from ATP hydrolysis (10). ATP is hydrolyzed by the proton-ATPase, located in the vesicular membrane, and the protons transported inside the vesicles give rise to a proton-electrochemical gradient that serves as the driving force for the vectorial transport of glutamate into the vesicles. Alternatively, Valinomycin (17) and a high extra-vesicular concentration of potassium can be used in order to generate a driving force. Valinomycin makes the membranes vectorially, and uni-directionally, permeable for potassium, and for a few minutes, the potassium gradient imposed by the high external potassium concentration, as opposed to the zero intravesicular potassium, can serve as driving force for glutamate transport across the membrane. In the presence of Valinomycin, the reagent Nigericin, which makes the membrane bi-directionally permeable for potassium ions, is used as a control in order to demonstrate that glutamate uptake is dependent on the potassium gradient. The Valinomycin approach is of interest in case it is uncertain the membranes tested contain a proton-ATPase, or as an additional tool to show that glutamate uptake is VGLUT1 dependent. In order to test for the uptake of glutamate $/{ }^{3} \mathrm{H}$-glutamate, and as it is was not known whether the crude High Five membrane fraction contained a proton ATPase, both ATP and high potassium/Valinomycin were added to the assay. In the experiments using membranes from VGLUT1Baculovirus infected insect cells, no difference in ${ }^{3} \mathrm{H}$-glutamate counts compared with the control $\beta$-adrenergic 2 receptor virus infected cells were observed (Fig. 5). Moreover, the absolute increase in counts was minimal (an increase in total counts over time is always observed due to non-specific ${ }^{3} \mathrm{H}$-glutamate binding). These data indicate that High Five VGLUT1 containing cell membrane fractions do not harbor a functional VGLUT1 transporter. Because of the overexpression of VGLUT1 it is likely that some of the protein could get transported/mislocalized to the plasma membrane where it could be present in a functional form. In order to test that idea, a passive ${ }^{3} \mathrm{H}$-glutamate exchange reaction assay was performed. In this assay, the cells are allowed to freely equilibrate and exchange intracellular glutamate with extracellular ${ }^{3} \mathrm{H}$-glutamate. If functional VGLUT1 were localized on the cell surface, one would expect such cells to take up more glutamate than control infected cell. As shown in Figure 6, no difference in passive glutamate uptake, as compared to control infected cells, were observed either one day or two days post infection. The one day time point was included as a previous report on SERT suggested that the insect cells become too leaky for uptake if infected for more than 20-36 hours (12). In summary, the data suggest that VGLUT1 expressed in High Five insect cells is not functional (Figs. 5 and 6).

\section{DISCUSSION}

\section{Expression of VGLUT1 in insect cells}

Roughly 100-200-fold more VGLUT1 protein/total protein was obtained with Baculovirus expression as compared to PC12 cell expression, but while VGLUT1 expressed in PC12 cells is active, that did not appear to be the case for the Baculovirus expressed protein. That VGLUT1 expressed in insect cells appears inactive is intriguing but not surprising. Previous reports provide mixed evidence that Baculovirus expressed membrane proteins indeed are active, and some reports claim functionality based on the mere binding of an inhibitor to the protein, and without demonstrating actual functionality (11-16). I hypothesize that the modest amount of ER and Golgi apparatus in insect cells, combined with the over-expression obtained by the Baculovirus, are grounds for the absence of activity observed, as the little membrane volume probably rapidly gets filled/aggregated with the recombinant VGLUT1's 9-11 transmembrane spanning domains. The detergent extraction data also indicate that a lot of the protein is already aggregated and that the remainder is difficult to extract from the membranes (confirming previous observations (14)) as compared with PC12 cells. Lack of 
glycosylation has been implicated as a cause for lack of Baculovirus expressed membrane protein activity (16). However, while PC12 VGLUT1 on the SDS-PAGE gels smears as a typical glycoprotein, expression with Baculovirus gives rise to three distinct bands as opposed to the one band one would expect if the protein were not at all glycosylated (the low molecular weight of the protein obtained in the transfection step may be explained by the lack of posttranslational modifications). Further studies will be required to determine whether (correct) glycosylation of VGLUT1 is required for functionality. Apart from glycosylation, lack of proteinatious (other subunits) or other non-proteinatious factors (i.e. cholesterol) could explain/add to the lack of activity. Obviously this study is not an exhaustive analysis of all the parameters that could be changed in the quest for obtaining functional protein, for example different promotors, and it remains a possibility that conditions can be determined where functional protein is obtained from over-expression in insect cells. However, I hypothesize that it seems most plausible that insect cells are simply not optimal for expression of membrane proteins (in particular not with as many as 9-11 transmembrane spanning domains) because of their modest content of intracellular endoplasmatic reticulum and Golgi membranes, and cautions to rely on Baculovirus-based expression systems for the over-expression of functional multi-membrane spanning membrane proteins.

By Western blotting, a prominent band at a molecular weight twice $(140-160 \mathrm{kD})$ that of monomeric $(70-80 \mathrm{kD})$ VGLUT1 is observable for both the PC12 and Baculovirus expressed protein (Figs. 1, 2, and 4; (8)). Moreover, while the samples were prepared at room temperature in standard Laemmli buffer (containing SDS and $\beta$-mercaptoethanol), if the samples were boiled prior to loading on the gel, even more extensive aggregation occurred (data not shown), and supporting that VGLUT1 has a strong tendency to oligomerize. This data indicate that the active transporter might function as a (homo)dimer, and I suggest they support a dimer-hypothesis previously proposed for amine transporter proteins (5).

\section{Reconstitution of vesicular synaptic glutamate uptake}

A primary goal of the experiments described here is to fully reconstitute glutamate filling of synaptic vesicles from purified components. The concentration of the excitatory amino acid glutamate in synaptic vesicles is estimated at a $100-150 \mathrm{mM}$ concentration (2). However, this has for technical reasons never been directly measured. It appears it should soon be possible to use fluorescently labeled glutamate to measure directly the vesicular glutamate content in vivo. The amount of glutamate in synaptic vesicles is of fundamental importance for the regulation of the size of the post-synaptic response elicited by the release of a single synaptic vesicle at the pre-synaptic membrane (the quantal size; (3)). Glutamate containing lipid-detergent vesicles can be prepared using crude soybean phospholipids (18), a glutamate containing solution, the detergent $\beta$-octylglucoside, and, for detergent removal, gel filtration spin columns ((19); Andersen SSL, unpublished data). Preliminary experiments using this preparation, and based on direct NADP/NADPH-based fluorimetric measurements (20), indicate that at physiological $\mathrm{pH}$ 7.4, the maximal obtainable glutamate-filling of the pure vesicles is reached using a buffer containing $50 \mathrm{mM}$ glutamate. Higher concentrations of glutamate $(120 \mathrm{mM})$ did not increase (or decrease) the amount of glutamate trapped in the vesicles, and I suggest this indicates that the upper limit for vesicular glutamate content may be in the $50 \mathrm{mM}$ range rather than in the estimated 100-150 mM concentration range (Andersen SSL, unpublished data). It will be interesting to continue further with the characterization of these pure lipid-detergent vesicles, and further expand the system by incorporating pure VGLUT1. However, rather than attempting to obtain sufficient VGLUT1 from PC12 cells, in a first instance VGLUT1 could be obtained from calf brains where it is very abundant (18). Once lipid-detergent VGLUT1 containing vesicles have been reconstituted using calf brain VGLUT1, the use of recombinant/mutated VGLUT1 from PC12 cells, or other source, will be required to further address mechanistic questions. For reconstitution, it will also be required to add a pure proton ATPase to the system. The proton ATPase may for reconstitution purposes be obtained as a side-fraction from the calf brains, or replaced by Bacteriorhodopsin (7) or omitted and replaced by Valinomycin and a potassium gradient. Reconstitution of the filling of synaptic vesicles with glutamate will in this manner be build up from purified components, and will provide fundamental answers both to the concentrationrange of glutamate in synaptic vesicles and to the mechanisms of vesicular glutamate uptake/transport (6).

\section{ACKNOWLEDGMENTS}

I am grateful to Dr. Richard Reimer for support, discussions and advice, and also to Brian Masselink and Marcin Wlizla for an enjoyable time as well as good ones during the work. The work was supported by a Stanford University start-up grant to Dr. Richard Reimer, and requests for materials should be addressed to: rjreimer@stanford.edu. I am very thankful to the following people at Stanford for their continued support, advice and supply of reagents and/or equipment during the performance of this work: Dr. Charles Parnot, Dr. Aaron Schaeffer, Alex Bankovich, Dr. Mark Bowen, Dr. Pavel Stroop, and to the following laboratories: Brunger lab, Kobilka lab, Mobley lab, Zarin lab, Garner lab, Garcia lab, Yang lab. Thanks to "anonymous" reviewers for valuable suggestions.

\section{REFERENCES}

1. Murthy VN, De Camilli P. Cell biology of the presynaptic terminal. Annu Rev Neurosci 2003; 26:701-728.

2. Burger PM, Mehl E, Cameron PL, Maycox PR, Baumert M, Lottspeich F, De Camilli P, Jahn R. Synaptic vesicles immunoisolated from rat cerebral cortex contain high levels of glutamate. Neuron 1989; 3:715-720.

3. Stevens CF. Neurotransmitter release at central synapses. Neuron 2003; 40:381-388.

4. Williams J. How does a vesicle know it is full? Neuron 1997; 18:683-686. 
5. Johnson RG Jr. Accumulation of biological amines into chromaffin granules: a model for hormone and neurotransmitter transport. Physiol Rev 1988; 68:232-307.

6. Wolosker H, de Souza DO, de Meis L. Regulation of glutamate transport into synaptic vesicles by chloride and proton gradient. J Biol Chem 1996; 271:11726-11731.

7. Maycox PR, Deckwerth T, Jahn R. Bacteriorhodopsin drives the glutamate transporter of synaptic vesicles after coreconstitution. EMBO J 1990; 9:1465-1469.

8. Bellocchio EE, Hu H, Pohorille A, Chan J, Pickel VM, Edwards RH. The localization of the brain-specific inorganic phosphate transporter suggests a specific presynaptic role in glutamatergic transmission. J Neurosici 1998; 18: 8648-8659.

9. Bellocchio EE, Reimer RJ, Fremeau RT Jr., Edwards RH. Uptake of glutamate into synaptic vesicles by an inorganic phosphate transporter. Science 2000; 289:957-960.

10. Reimer RJ, Fremeau RT Jr., Bellocchio EE, Edwards RH. The essence of excitation. Curr Opin Cell Biol 2001; 13:417421.

11. Tate CG, Blakely RD. The effect of N-linked glycosylation on activity of the $\mathrm{Na}(+)$ - and $\mathrm{Cl}(-)$-dependent serotonin transporter expressed using recombinant baculovirus in insect cells. J Biol Chem 1994; 269:26303-26310.

12. Tate CG. Baculovirus-mediated expression of neurotransmitter transporters. Methods Enzymol 1998; 296:443-455.

13. Sievert MK, Thiriot DS, Edwards RH, Ruoho AE. Highefficiency expression and characterization of the synaptic- vesicle monoamine transporter from baculovirus-infected insect cells. Biochem J 1998; 330:959-966.

14. Lu ML, Huang YW, Lin SX. Purification, reconstitution, and steady-state kinetics of the trans-membrane 17 betahydroxysteroid dehydrogenase 2. J Biol Chem 2002; 277:22123-22130.

15. Klaassen CH, Bovee-Geurts PH, Decaluwe GL, DeGrip WJ. Large-scale production and purification of functional recombinant bovine rhodopsin with the use of the baculovirus expression system. Biochem J 1999; 342:293-300.

16. Tate CG, Haase J, Baker C, Boorsma M, Magnani F, Vallis Y, Williams DC. Comparison of seven different heterologous protein expression systems for the production of the serotonin transporter. Biochim Biophys Acta 2003; 1610:141-153.

17. Reed PW. Ionophores. Methods Enzymol 1979; 55:435-454.

18. Lewis SM, Ueda T. Solubilization and reconstitution of synaptic vesicle glutamate transport system. Methods Ensymol 1998; 296:125-144.

19. Maduke M, Pheasant DJ, Miller C. High-level expression, functional reconstitution, and quaternary structure of a prokaryotic ClC-type chloride channel. I Gen Physiol 1999; 114:713-722.

20. Nicholls DG, Sihra TS, Sanchez-Prieto J. Calciumdependent and -independent release of glutamate from synaptosomes monitored by continuous fluorometry. $J$ Neurochem 1987; 49:50-57. 